\title{
A family-based model to predict fear of recurrence for cancer survivors and their caregivers
}

\author{
Suzanne Mellon ${ }^{\prime}$, Trace S. Kershaw ${ }^{2}$, Laurel L. Northouse ${ }^{3}$ and Laurie Freeman-Gibb ${ }^{4}$ \\ I University of Detroit Mercy, College of Health Professions, 400I W. McNichols, Detroit, MI, USA \\ 2 Yale University, Department of Epidemiology and Public Health, New Haven, CT, USA \\ ${ }^{3}$ School of Nursing, University of Michigan, Ann Arbor, MI, USA \\ ${ }^{4}$ Karmanos Cancer Institute, Detroit, MI, USA
}

* Correspondence to: University of Detroit Mercy, College of Health Professions, 400 I W. McNichols, Detroit, MI, USA. E-mail: mellonsk@udmercy.edu

Received: 12 September 2005

Revised: 23 April 2006

Accepted: I May 2006

\begin{abstract}
Although fear of cancer recurrence is a great concern among survivors and their families, few studies have examined predictors of fear of recurrence. The purpose of this study was to identify factors associated with fear of recurrence in a population-based sample $(N=246)$ and determine if survivors and family caregivers influenced one another's fear of recurrence. A family framework guided the study and analyses included multilevel modeling using the Actor-Partner Interdependence Model. Results indicated that survivors and family caregivers influenced each other's fear of recurrence and that caregivers had significantly more fear of recurrence than survivors. More family stressors, less positive meaning of the illness, and age were related to elevated fear of cancer recurrence for both survivors and caregivers. Copyright (C) 2006 John Wiley \& Sons, Ltd.
\end{abstract}

Keywords: fear of recurrence; cancer; survivorship; family caregiver

\section{Introduction}

A large and growing cohort of cancer survivors has generated new interest in the concerns they experience after successfully completing treatment. Currently there are over nine million cancer survivors in the United States [1]. One of the major concerns cancer survivors report is the fear that the cancer will return [2-4]. This fear also extends to the family members of cancer survivors [5,6]. Fear of recurrence is rapidly becoming a universal concern during survivorship, and has been linked to poorer psychological adjustment, increased emotional distress and lower quality of life outcomes for survivors $[7,8]$ and their family members $[6,9]$. However, information is lacking on factors that enhance or diminish fear of recurrence and on how survivors and family members influence one another's fear. Further research on fear of recurrence is essential in order to help survivors and family members find ways to manage this pervasive fear and maintain their quality of life.

Using a family stress-coping framework, the purpose of this study was to: (1) identify factors associated with fear of recurrence in a populationbased sample of cancer survivors and their family members, (2) determine the extent to which survivors and family members influenced one another's fear of recurrence, and (3) assess differences in predictors of fear of recurrence between survivors and family caregivers.

\section{Background}

\section{Studies on fear of recurrence}

In spite of the numerous anecdotal reports of fear of recurrence among cancer survivors, there have been few systematic studies of this phenomenon. The few studies that have been conducted indicate that it is a commonly reported fear among cancer survivors that persists over time [10-12]. Stanton and colleagues [7] found moderate levels of fear of recurrence in breast cancer survivors and no change in their fear from 3 to 12 months postdiagnosis. Other investigators have reported persistent fear of recurrence in long-term cancer survivors even though they were no longer in the acute phase of illness $[4,11,12]$.

Surprisingly, investigators have found that family members have more fear of recurrence or worry than do survivors themselves [3,13-15]. Some investigators contend that survivors may be more preoccupied with the day-to-day aspects of the illness, which distracts them from long-range concerns about the illness [13]. Although the specific explanation for family members' greater fear warrants further study, it is clear that fear of recurrence is a persistent fear of both survivors and their family members.

Even though fear of recurrence appears to be universal, some survivors report more fear than others. Vickberg [8] found that about half of the 
women with breast cancer in her study had moderate to strong fear, while the remaining half of the sample had very little fear. Mathews et al. [16] reported that there was a subset of the survivors in their study $(31 \%)$ who had very high worry about recurrence (i.e. two standard deviations above the mean reported by the matched controls), while other survivors had less fear. These studies suggest that some survivors may be at greater risk of higher fear of recurrence than others.

Although fear of recurrence is fairly commonplace among survivors and their family members, it is related to a number of negative outcomes. Higher fear of recurrence is associated with significantly higher emotional distress $[7,8]$, more intrusive thinking [8], lower vigor [7], lower wellbeing in cancer survivors [8] and lower quality of life among family members $[9,17]$. In addition, survivors in one study who reported a high degree of worry said that it negatively affected their daily routine and interpersonal relationships [15]. Given the detrimental effects that fear of recurrence can have on survivors and their family members, further research needs to identify factors associated with fear of recurrence so that interventions can be developed to lessen this fear.

\section{Factors associated with fear of recurrence}

A family stress-coping framework, adapted from McCubbin and McCubbin's resiliency model [18], was used to guide this study and the selection of factors that may be associated with fear of recurrence. This model was adapted to examine possible predictors of fear of recurrence for both survivors and family caregivers. According to the framework shown in Figure 1, the family's ability to adapt depends on personal factors (i.e. demographics), the number of stressors families face (concurrent family stressors and illness-related stressors), the family's resources (family hardiness and social support), and the family's appraisal of their situation (meaning of the cancer illness). The model also suggests that a reciprocal relationship exists between the level of fear reported by survivors and their family members; each partner affects the other (see Figure 1).

Among personal factors shown in Figure 1, younger age has been associated with more stressful appraisals of cancer [19] and more fear of recurrence $[5,7,8,20,21]$. Few studies have examined education, but Gil et al. [22] reported that more educated women had more triggers about recurrence than less educated women. In regard to gender, female survivors have reported more fear of recurrence than male survivors [13] and female caregivers more fear than male caregivers [3]. Although few studies have examined race, African-American survivors (mean 10 years post-diagnosis) have reported less stressful appraisals of the cancer than Caucasian survivors [19] and fewer triggers of fear of recurrence [22].

According to the model, various stressors may directly or indirectly affect fear of recurrence (see Figure 1). Cancer survivors and their family members who report more concurrent family stressors also report more negative appraisals of the cancer, more emotional distress, and lower quality of life $[23,24]$. There are also a number of illness-related stressors that may influence fear of cancer recurrence. A shorter time since diagnosis has been associated with more fear of recurrence in some studies of cancer survivors [4] and their family members [5], but not in other studies $[12,15,22]$. Other health problems, experienced by survivors or family members, may be related to more fear of recurrence but this factor has not been explored in prior research. Finally, survivors who report more somatic concerns (e.g. fatigue), also report more negative appraisals of the illness, poorer adjustment to the illness [10,16,20,25,26], and may have higher fear of recurrence.

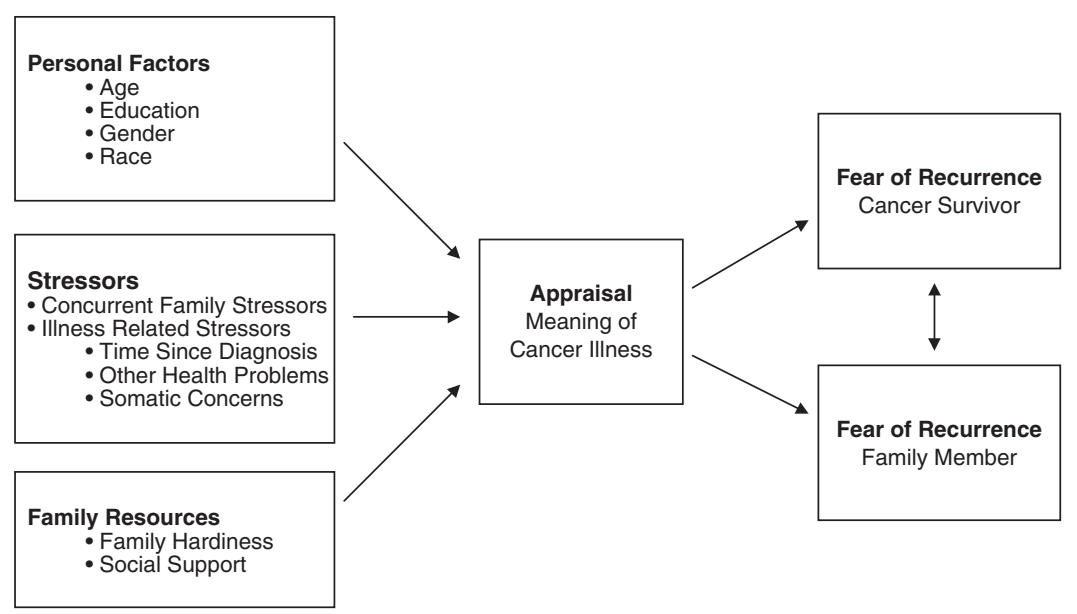

Figure I. Family model of predictors of fear of recurrence 
Family resources also may affect appraisal and fear of recurrence (see Figure 1). Northouse et al. [24] found that family caregivers of breast cancer patients who had more family hardiness had less uncertainty, less hopelessness, and better quality of life. Higher social support has been associated with more positive meaning derived from the cancer [27], less worry [15], and less fear of recurrence among cancer survivors [12].

According to the model, appraisal or the meaning of the illness to cancer survivors and their family members may mediate the relationship between the antecedent factors and fear of recurrence (see Figure 1). Several studies have found that the more cancer survivors and family members appraise the cancer experience as threatening, the more it negatively affects their emotional adjustment and quality of life [28,29].

Finally, the model specifies that an interrelationship exists between the fear of recurrence of cancer survivors and their family members (see Figure 1). Several studies have documented the mutual influence that patients and family members have on each other's adjustment and quality of life [30-32]. These studies suggest that patients' and family members' responses to cancer are interdependent; each affects the other as indicated in Figure 1. Further research is needed, however, to determine the extent to which the fear of recurrence is related in cancer survivors and family members during long-term survivorship.

The specific research questions guiding this study were: (a) What is the contribution of personal factors (age, education, gender, and race), stressors (concurrent family stressors and illness-related stressors), family resources (family hardiness and social support), and appraisal (meaning of the illness) to fear of recurrence of both the cancer survivor and family member? (b) Does appraisal of the illness mediate the effect of personal factors, stressors, and family resources on fear of recurrence? (c) Is there an interrelationship between the fear of recurrence of the cancer survivor and the family member? And, (d) do these relationships differ between cancer survivor and family member?

\section{Methods}

This study was a secondary analysis of a large, population-based study designed to examine factors associated with quality of life in cancer survivors and their family members [9,17]. Since fear of recurrence was an important predictor of family quality of life outcomes in the parent study, this secondary analysis was conducted to examine factors that contribute to fear of recurrence.

\section{Sample}

A population-based sample was identified from the Metropolitan Detroit Cancer Surveillance System (MDCSS), a cancer registry and founding participant in the National Cancer Institute SEER Program. The registry collects diagnostic, pathology, and treatment data along with demographics of all persons diagnosed with cancer occurring in a 3-county region of metropolitan Detroit. A sample was randomly selected from the registry of patients that was stratified by race (e.g. Caucasian and African-American) and by cancer site (e.g. breast, colon, prostate, uterine). Other eligibility criteria specified that survivors were: 1-5 years postdiagnosis, had a cancer stage of I-III, and were 50-70 years old at the time of diagnosis. These criteria were chosen to target a survivor population that was within a specified period of time postdiagnosis, within an older age range to increase sample homogeneity, and at an earlier stage of illness to minimize likelihood of recurrence or distant metastasis. Using these criteria, 373 cancer survivors were identified from the SEER Registry.

There were additional eligibility criteria that could not be determined from the SEER registry but had to be assessed by contacting the potential participant. These additional criteria included that the survivors: had completed primary treatment at least one year prior to participation, were not in a recurrent or terminal stage of the illness, and had an eligible family member willing to participate in the study. 'Family caregiver' was broadly defined as a family member or significant other who was over 18 years of age. The survivor selected the person who had been his/her primary source of support during the cancer experience.

Of the 373 survivors contacted, 82 were unable to be contacted (incorrect addresses or had moved out of the area), 10 had died, and 74 individuals did not meet the additional study criteria when contacted by phone. Of the eligible survivors who could be reached $(N=207), 84$ survivors declined study participation. Reasons for declining included: lack of interest, no time, other stressors, anxiety about the cancer, and current involvement in other research studies. The final sample who participated in the study consisted of 123 dyads (enrollment rate $60 \%$ ). We compared those who participated with non-participants on demographic variables, and found only one significant difference. Study participants were significantly older than non-participants.

\section{Procedure}

After obtaining institutional review board approval, the procedure for sample accrual followed standard registry protocols. Registry staff sent letters to the survivor's physician to notify them 
of the study and to determine if survivors were eligible to participate. The registry uses a passive consent process; thus, if there was no response from physicians within two weeks, registry staff proceeded to contact the survivors to obtain their permission to release their name to the research team. Survivors willing to be contacted were sent a letter that further described the study. After about a week, a member of the research team made a follow-up telephone call to survivors to determine their interest in participation along with an eligible family member.

All data collection sessions were approximately one hour in length and took place in the survivor's home or another site selected by the family. Master's prepared nurses obtained the data from both the survivor and family member during the same visit, but each person completed the selfreport questionnaires alone. Written informed consent was obtained for all participants prior to their participation in the study. No additional incentive was given to participants in the study.

\section{Sample characteristics}

The average age of the cancer survivor was $65 \pm 6.2$ years (range, 52-75 years) and the average age of the family caregiver was $55 \pm 14.5$ years (range, 21-80 years). Since the sample was stratified on race, slightly more than half $(50.4 \%)$ of the family dyads were Caucasian and half (49.6\%) were African-American. In this population-based sample, the mean years of education reported by patients were 12.3 years and for family members 13.2 years. Family income ranged from $10.6 \%$ with incomes less than $\$ 10000$ to $7.3 \%$ with incomes over $\$ 90000$. The majority of families $(65 \%)$ fell between $\$ 11000$ and $\$ 60000$. The majority of family caregivers participating were either spouses $(52.8 \%)$ or adult children $(29.3 \%)$. Other relationships represented in this sample were siblings $(8.1 \%)$ and significant others/extended family members $(9.7 \%)$. Additionally, a majority of the survivors were married $(64.2 \%)$.

Since the sample was stratified on diagnosis, there were nearly equal groups of survivors in four cancer diagnostic categories: 31 breast, 31 colon, 31 uterine, and 30 prostate cancer survivors. A variety of treatment modalities were represented: surgery $(87.8 \%)$, radiation $(39 \%)$, chemotherapy $(22.8 \%)$, and hormone therapy $(3 \%)$. The majority of the survivors $(56.1 \%)$ had only one type of treatment (surgery or radiation), while one-third of the survivors had a combination of two treatments (surgery/radiation; surgery/hormone; surgery/chemotherapy; radiation/hormone). A small number $(n=11)$ of survivors had three types of treatment, and four survivors had a total of four types. The time since diagnosis for this sample of survivors ranged from 1.5 to 6 years $(M=3.4)$ and the time since the primary treatment was completed was 1-6 years $(M=3.0)$. Over $73 \%$ of the survivors and $50 \%$ of family caregivers also reported other health problems, such as heart disease, arthritis, or diabetes.

\section{Measures}

A researcher-designed questionnaire was used to obtain personal information related to participants' age, education, gender, and race. Additional information also was obtained on family composition and the role relationship of survivor to caregiver (i.e. spouse, sibling, adult child).

Concurrent family stressors. An earlier version of the Family Pressures Index [33] was used to measure the other concurrent family stressors that survivors and family members perceived as being present for their families within the past year. This version of the instrument was a 64-item scale with an additional 8-item distress subscale that evolved out of the Family Inventory of Life Events (FILE; e.g. [34]. This adapted instrument measures the stressors that families of today may experience (job problems, effect of prejudice, concern for abuse of alcohol/drugs, family conflict). A higher score indicates more stressors for a family. Adequate reliability and validity have been reported for the Family Pressures Index [35]. The Cronbach's alpha reliability coefficient for survivors was 0.91 and 0.92 for family caregivers in this study.

Illness-related stressors were measured with an investigator-developed instrument that identified medical characteristics, including the primary cancer site, time since diagnosis and completion of primary treatment, and other non-cancer-related health problems of both the survivor and family caregiver. Information on survivors' somatic concerns was measured with the physical well-being subscale of the Functional Assessment of Cancer Therapy Scale (Fact G) [36]. This 7-item subscale was used to capture any lingering symptoms or physiological problems that survivors were still experiencing. Evidence of adequate reliability and validity of this widely used FACT instrument has been reported previously [36]. This instrument was completed only by the survivor, with an $\alpha$ coefficient of 0.67 .

Family hardiness. The 20-item Family Hardiness Index (FHI; [37]) was used to measure family hardiness, conceptualized as a family's degree of internal strengths and resiliency. The instrument contains four subscales: co-oriented commitment, confidence, challenge, and control. Only total scale scores were used in the analyses for this study. Evidence of reliability and validity has been reported previously [37]. In this study, the alpha reliability for the total score was 0.78 for survivors and 0.80 for family caregivers. 
Social support. The Social Support Index (SSI; [38]), a 17-item scale that measures the degree to which families give support to its members, view the community as a source of support, and feel that the community context can provide emotional, esteem, and network support. A 5-point Likert scale was used, with higher scores indicating more social support. Evidence of internal consistency, test-retest reliability, and concurrent validity has been reported [38]. The alpha reliability for social support for survivors was 0.73 and 0.77 for family caregivers.

Meaning of illness. The Constructed Meaning Scale [27] was used to measure the meaning of cancer to the family unit by both the survivor and family member. The scale has a total of eight items that include statements referencing the effects of the illness on the individual's identity, interpersonal relationships, and the future. The scale was adapted for this study to measure the meaning of cancer to the entire family unit, rather than only individually. There are four possible responses for each item, ranging from 'strongly disagree' (1) to 'strongly agree' (4). Higher scores indicate a more positive meaning of the cancer experience, while a lower score denotes a more negative or pessimistic meaning. Psychometric properties of the original scale have been reported with adequate reliability and validity [27,39]. Reliability scores for the adapted instrument in this study were 0.77 for survivors and 0.78 for family caregivers.

Fear of recurrence. The Fear of Recurrence Questionnaire [12] was used to measure the amount of worry and concern that survivors and family members have about the cancer returning in the future. The 22-item instrument uses a Likert scale format with both positively- and negatively worded items. A modified version of the scale was completed by family caregivers to report the amount of concern they had regarding their family member's cancer recurring. Negatively worded items were reverse-scored prior to creating the summary score. A higher score on the scale indicates a higher fear of recurrence. Psychometric properties of the scale, including adequate content validity and reliability, have been reported in prior studies of breast cancer patients $[12,21]$. In the present study, the reliability coefficients for survivors were 0.92 and 0.91 for family caregivers.

\section{Data analysis}

To assess relationships among variables, Pearson correlations (for continuous predictors) and point biserial correlations (for categorical predictors) were conducted for all study variables for survivors and caregivers separately. Next, to assess the proposed model for the effect of survivors and family caregivers on one another, we conducted the Actor-Partner Interdependence Model (APIM) using multilevel modeling with PROC MIXED in SAS 8.2 [40-44].

Multilevel modeling (or hierarchical linear modeling) to estimate APIM treats the members of a dyad as nested scores within the same group [40,41]. This approach to estimate APIM has been widely used by researchers (e.g. [45-48]) and has several advantages over pooled regression and structural equation modeling (SEM) approaches [40]. The multilevel modeling approach is less computationally complex, more flexible, and better able to easily model and assess interactions than pooled regression and SEM approaches to assessing APIM [40]. A detailed description on how to conduct APIM analyses using multilevel modeling programs (e.g. HLM and SAS PROC MIXED) has been previously outlined (see, [40]) and served as the guide for our analysis plan.

The heart of the APIM approach is to assess actor and partner effects. Actor effects refer to whether a person's score on a predictor variable influences the person's own outcome (i.e. either survivor or family caregiver influences self). Partner effects refer to whether a partner's score on the predictor variable influences another person's outcome (i.e. family caregiver influences survivor or survivor influences family caregiver) [40,44].

In APIM there are three types of predictor variables that can be used: within dyad variables, between dyad variables, and mixed variables. Within dyad variables differ between members of the dyad but have the same value across dyads (e.g. role of survivor vs family caregiver). Between dyad variables are the same for members of the dyad but differ across dyads (e.g. time since diagnosis). Mixed variables occur when scores can differ both within and between dyads (e.g. age, other health problems, family stressors, family hardiness, social support and family meaning). With APIM, actor and partner effects are only assessed for mixed variables. Main effects are assessed for within dyad variables or between dyad variables.

Since the family model (see Figure 1) hypothesizes that meaning of the illness mediates the relationships between the predictors and fear of recurrence, mediation was assessed using a modification of the approach outlined by Baron and Kenny [49]. First, an APIM model assessed the influence of the predictors on meaning. Second, an APIM model assessed the influence of the predictors on fear of recurrence. Third, an APIM model assessed the influence of the predictors plus the mediator on fear of recurrence.

Finally, to assess whether any of the actor and partner relationships differed between survivor and family caregiver (i.e. whether there were different predictors of fear of recurrence for survivors and family caregivers), a set of interactions between role and all predictor variables were entered one at a time in the final model [50]. Any significant 
interactions were added to the final model. It is important to understand potential differences in factors that relate to fear of recurrence between survivors and family caregivers in order to develop effective family based interventions that reduce fear for both survivors and caregivers.

In order to increase the interpretability of the regression coefficients and because interaction terms were modeled, all variables were centered [51] using the mean from the combined data, which is the recommended approach when centering variables in the APIM model [40]. The actor and partner effects presented in the model are unstandardized regression coefficients (and their standard errors).

\section{Results}

Table 1 shows the relationships between the predictor variables and fear of recurrence for both survivors and caregivers. Survivors and family caregivers who reported more family stressors in their lives and less meaning associated with the illness had more fear of recurrence. Among survivors only, those who reported other health problems and more somatic symptoms also reported higher fear of recurrence. Medical factors such as type of cancer, stage of cancer, and type of treatment received were not related to survivors' or family caregivers' fear of recurrence.

Next, multilevel modeling was conducted using APIM analysis to assess the model proposed in

Table I. Correlation of personal, social, illness, and appraisal factors with fear of recurrence for survivors and caregivers

\begin{tabular}{|c|c|c|}
\hline & \multicolumn{2}{|c|}{ Fear of recurrence } \\
\hline & $\begin{array}{c}\text { Survivors } \\
r\end{array}$ & $\begin{array}{c}\text { Caregivers } \\
r\end{array}$ \\
\hline \multicolumn{3}{|l|}{ Personal factors } \\
\hline$A g \mathrm{e}^{\mathrm{a}}$ & -0.15 & 0.02 \\
\hline Education $^{\mathrm{a}}$ & 0.03 & 0.08 \\
\hline Gender $^{\mathrm{b}}$ & 0.04 & -0.02 \\
\hline Race $^{b}$ & 0.10 & -0.12 \\
\hline \multicolumn{3}{|l|}{ Stressors } \\
\hline Concurrent family stressors ${ }^{\mathrm{a}}$ & $0.31 * * *$ & $0.29 * *$ \\
\hline Time since diagnosis ${ }^{\mathrm{a}}$ & 0.05 & 0.01 \\
\hline Other health problems ${ }^{\mathrm{b}}$ & 0.35 *** & -0.02 \\
\hline Somatic concerns ${ }^{a}$ & $0.19 *$ & 0.15 \\
\hline \multicolumn{3}{|l|}{ Family resources } \\
\hline Family hardiness $^{\mathrm{a}}$ & -0.16 & -0.09 \\
\hline Social support ${ }^{a}$ & -0.15 & -0.05 \\
\hline \multicolumn{3}{|l|}{ Appraisal } \\
\hline Meaning of cancer illness ${ }^{\mathrm{a}}$ & $-0.43 * *$ & $-0.28 * *$ \\
\hline
\end{tabular}

Figure 1. First, an APIM model was assessed for the set of predictors on meaning of the illness. Only two variables had a significant actor effect on perceived meaning of illness: family hardiness $(b=0.13, \mathrm{SE}=0.04, t=3.77, p<0.05)$ and social support $(b=0.10, \mathrm{SE}=0.04, t=2.60, p<0.05)$. The more family hardiness and social support individuals (both survivors and caregivers) perceived, the more positive the meaning associated with the illness. No significant partner effects were found for meaning of the illness. Therefore, only the actor effects for family hardiness and social support could be further examined to determine if their effects on fear of recurrence were mediated by meaning of the illness [49].

To assess whether the relationships between family hardiness and social support on fear of recurrence were mediated by meaning, these two variables had to demonstrate a direct relationship with fear of recurrence without meaning in the model. A multilevel model was conducted to assess the influence of these predictors on fear of recurrence. Results showed that neither family hardiness nor social support related to fear of recurrence (both $p>0.05$ ). Therefore, the mediation proposed in Figure 1 was not supported.

To assess the influence of all of the predictors on fear of recurrence, a final model was tested that examined all variables simultaneously including meaning. Results are depicted in Table 2. The results showed significant actor effects for concurrent family stress and meaning. Individuals (survivors and family caregivers) who reported more family stress and less positive meaning had more fear of recurrence. No other significant actor effects were found. An individual's (survivor and caregiver) perceived level of family hardiness and social support did not significantly influence the individual's fear of cancer recurrence.

To assess whether any actor effects differed significantly between survivor and caregivers, differences of actor effects between survivor and caregiver were tested. A marginally significant meaning of illness by relationship role (survivor vs caregiver) interaction effect was found $(p=0.06)$. Simple effects showed that even though less meaning of illness significantly related to more fear of recurrence for both survivors and caregivers, the relationship was stronger for survivors $(b=-1.34)$ than for caregivers $(b=-0.64)$.

In regard to partner effects in the APIM analyses, results showed only one significant partner effect and that was for age of partners. When the age of the survivor decreased, the caregiver's fear increased. Similarly, when the age of the caregiver decreased, the survivor's fear increased. No other significant partner effects were found. Neither survivors' nor family caregivers' levels of stress, perceived hardiness, social support, and perceived meaning had a significant influence 
on the fear of recurrence of the other member in the dyad.

To assess whether any partner effects significantly differed between survivor and caregivers, differences of partner effects between survivor and caregiver were tested. Results showed a significant

Table 2. The influence of personal, social, illness and appraisal factors on fear of recurrence

\begin{tabular}{|c|c|c|c|c|}
\hline & $b$ & SE & $t$ & $p$ \\
\hline \multicolumn{5}{|l|}{ Personal factors } \\
\hline \multicolumn{5}{|l|}{ Age } \\
\hline Actor effect & 0.11 & 0.24 & 0.46 & 0.69 \\
\hline Partner effect & -0.52 & 0.24 & -2.12 & $0.04 *$ \\
\hline Education & 1.01 & 1.12 & 0.90 & 0.33 \\
\hline Gender (patient) & 0.99 & 2.55 & 0.39 & 0.70 \\
\hline Race & 0.58 & 1.44 & 0.41 & 0.69 \\
\hline \multicolumn{5}{|l|}{ Stressors } \\
\hline \multicolumn{5}{|l|}{ Concurrent family } \\
\hline \multicolumn{5}{|l|}{ Stressors } \\
\hline Actor effect & 0.34 & 0.10 & 3.37 & 0.00 I **⿻丷木 $^{2}$ \\
\hline Partner effect & 0.04 & 0.10 & 0.41 & 0.68 \\
\hline Time since diagnosis & 0.43 & 1.18 & 0.37 & 0.72 \\
\hline \multicolumn{5}{|l|}{ Other health problems } \\
\hline Actor effect & 4.75 & 2.46 & 1.95 & 0.054 \\
\hline Partner effect & 3.27 & 2.46 & 1.34 & 0.18 \\
\hline Somatic concerns & 1.75 & 1.16 & 1.50 & 0.14 \\
\hline \multicolumn{5}{|l|}{ Family resources } \\
\hline \multicolumn{5}{|l|}{ Family hardiness } \\
\hline Actor effect & 0.16 & 0.21 & 0.76 & 0.45 \\
\hline Partner effect & -0.24 & 0.21 & -1.19 & 0.24 \\
\hline \multicolumn{5}{|l|}{ Social support } \\
\hline Actor effect & 0.12 & 0.21 & 0.55 & 0.59 \\
\hline Partner effect & 0.21 & 0.21 & 0.96 & 0.34 \\
\hline \multicolumn{5}{|l|}{ Appraisal factor } \\
\hline \multicolumn{5}{|l|}{ Family meaning } \\
\hline Actor effect & -1.24 & 0.39 & -3.19 & 0.002 **⿻丷木 \\
\hline Partner effect & -0.23 & 0.39 & -0.59 & 0.56 \\
\hline \multicolumn{5}{|l|}{ Relationship role } \\
\hline $\begin{array}{l}\text { Survivor vs family } \\
\text { Caregiver }\end{array}$ & -4.89 & 1.13 & -4.33 & 0.00 I **⿻丷木 \\
\hline
\end{tabular}

partner age by relationship role (survivor vs caregiver) interaction $(p<0.05)$. This interaction shows that dyads comprised of older survivors with younger caregivers had more fear of recurrence than other dyads.

Results also indicated that the relationship role, a within dyad variable, influenced fear of recurrence. Family caregivers had significantly more fear of recurrence than patients (even after controlling for the other variables in the model). There were no significant relationships between gender, race, education, or time since diagnosis and fear of recurrence.

The partial intraclass correlation for the final model was 0.41 , indicating that after controlling for all the predictors, there was a significant and fairly strong correlation between survivors and family caregivers' fear of recurrence. This suggests that survivors and family caregivers mutually influenced each others' fear of recurrence. The final model after the APIM testing is shown in Figure 2.

\section{Discussion}

This study identified factors that had an independent and interdependent influence on survivors' and family caregivers' fear of recurrence during survivorship. Using APIM analyses, we found more 'actor effects' than 'partner effects'. In other words, we found that each person's own perceptions rather than their partners' perception exerted more influence on individuals' levels of fear of recurrence. Stressors and appraisal (i.e. meaning of the illness to the family), accounted for the most variance in both survivors' and family caregivers' fear of recurrence. In regard to stressors, survivors and family caregivers who reported more concurrent family stressors had more fear of cancer recurrence. This finding also is consistent with reports from other studies that more concurrent stress is associated with higher emotional distress and lower quality of life among cancer survivors

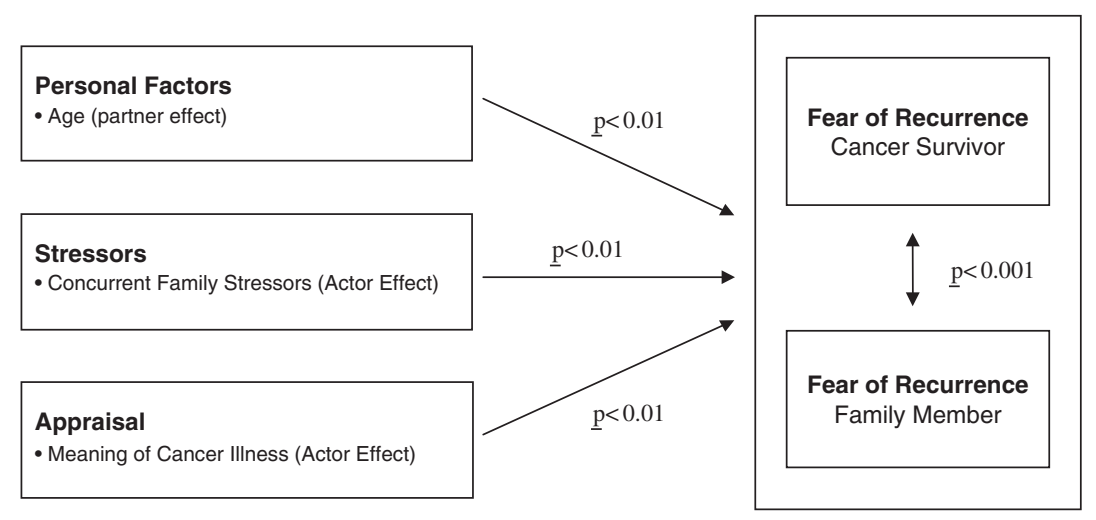

Figure 2. APIM Model of predictors after testing (model depicts only significant relationships with outcomes after testing) 
and their family members [23,24]. Concurrent family stress may drain survivors' and family caregivers' mental energy and use up coping resources that would otherwise be available to help them manage the threat of cancer recurrence. We also found that other health problems were related to more fear of recurrence in survivors. These illness-related stressors may further exacerbate concerns about fear of recurrence for cancer survivors.

Another 'actor' effect influencing fear of recurrence was meaning of the illness. Survivors and family caregivers who reported more positive meaning associated with the illness had significantly less fear of recurrence. It was each individual's own meaning of the illness, rather than the influence of their partner's meaning, that affected each individual's own fear of recurrence. A number of other investigators have also found a significant relationship between finding meaning in a cancer illness and positive health outcomes such as better adjustment, less anxiety, less depression, and improved role functioning [39,52]. This suggests that individual appraisal, or the meaning of cancer, may be an important factor for reducing risk susceptibility to long-term distress in survivors and their family members.

There was only one 'partner' effect in our study, with findings suggesting that age has a differential influence on fear of recurrence. In all dyads, when the partner's age decreased, both the survivor's and caregiver's fear of the cancer returning increased. Thus, survivors with younger caregivers and caregivers with younger survivors both experienced more fear. Survivors may worry about the wellbeing of their younger caregiver who may be left with greater family disruption and economic hardship if the cancer returns. Similarly, caregivers with younger survivors may worry about the potential loss of their loved one earlier than expected in life.

There were also significant within dyad effects, specifically in the role relationship in the family. Family caregivers had significantly more fear of recurrence than survivors. This finding is consistent with other studies that report family members are more distressed and worried about the future than the cancer survivor themselves [3,13,31]. Ell and colleagues [53] suggest that having less personal control, less social support and greater stress overall contributes to family members' problems adjusting to their loved one's cancer. Perhaps family caregivers who are standing by to provide support to the survivor do not address their own personal fears or are reluctant to burden the cancer survivor with their own fears. Hence, family caregivers may be less likely to work through or resolve their own fear of the cancer returning. This has important implications for long-term quality of life and role functioning outcomes within families if family caregivers' fears are not addressed.
Another important finding from this study was the interdependence between the survivors' and caregivers' fear of recurrence. As one family member's fear increased, so did the other member's. The interrelationship between family members' responses to cancer has been reported in other research [30-32, 54,55], and this study extends the family's mutual influence to the ongoing fear of recurrence prevalent during the extended survivorship period.

Overall, the proposed family-based theoretical model received partial support as shown in Figure 2. Certain personal characteristics, stressors, and meaning of the illness contributed to survivors' and family caregivers' fear of recurrence. Although we hypothesized that meaning of the illness would mediate the relationship between the antecedent factors (personal characteristics, stressors, and family resources) and fear of recurrence, it did not. Meaning had a direct effect on fear of recurrence, but was not a mediator in this study. Further, while age was found to be predictive of fear of recurrence, other personal factors were not. While some studies have detailed gender differences in survivorship and quality of life, only a few have begun to address gender in fear of recurrence $[3,13]$. Although we were expecting possible differences related to gender effects, with women having more fear than men, this was not found in our sample. A possible explanation is that age effects were more dominant than gender effects in this longer-term survivor population who were not in active treatment. Further study is warranted to determine if there is an interplay of age, gender, and treatment effects during long-term survivorship.

Other parts of the model, such as family resources, (family hardiness and social support), were also not related to fear of recurrence in this study. This was somewhat surprising in light of the positive relationships that have been reported between support and adjustment in previous studies $[12,56]$. However, in this study we chose to use more generic, community-based measures of family resources rather than cancer-specific measures because survivors were no longer in the acute phase of illness. While these instruments captured general support from family and the community, they did not capture the support available to assist survivors and family caregivers to deal with cancerspecific worries and concerns. This may account for the lack of relationship found between resources and fear of recurrence in this study.

This study had several limitations. Although we based our study on a theoretical model, several other potential variables could have been included. Other potential variables to consider include optimism [57], self-efficacy [58], active vs avoidant coping [7], family functioning [59] and family communication [5]. A second limitation is the 
retrospective, cross-sectional design of the study. The analysis and discussion of the findings imply some directionality that needs to be viewed with caution. Prospective, longitudinal studies are needed in order to establish directionality and causality among the associations found in this study. Another limitation is the study used selfreport assessments of health and well-being. Future studies may benefit from using both self-report and biological assessments of stress and health. Finally, some of the measures were adapted to be appropriate for family members (e.g. meaning of illness), which may have influenced some of the statistical relationships. However, it should be noted that these adapted scales still demonstrated adequate psychometric characteristics.

\section{Conclusion}

Overall, the results of this study indicate that both individual and dyadic factors are associated with the amount of fear of recurrence reported by long-term cancer survivors and their family caregivers. These findings underscore the importance of factoring in dyadic and family effects when studying cancer survivorship. Among individual factors, each person's own perception of the stressors within the family and the meaning they associate with the illness accounted for a significant amount of variance in their fear of recurrence. Among dyadic factors, the level of fear of recurrence experienced by one partner influenced the amount of fear experienced by the other. Furthermore, the younger age of one member of the dyad was associated with greater fear in the older member of the dyad. In view of the fact that fear of recurrence has been linked with the important outcomes of quality of life, distress, and psychosocial adjustment, it is critical to address potential factors that may influence both survivors' and family caregivers' fear of recurrence during long-term cancer survivorship.

\section{Acknowledgements}

This study was supported in part by the SEER NCI contract \# NOl-CN-65064 and by the Helen Newberry Joy Foundation, Wayne State University.

\section{References}

1. Rowland J, Mariotto A, Aziz N et al. Cancer survivorship-United States, 1971-2001. Morbidity Mortality Weekly Rev 2004;53(24):526-529.

2. Ashing-Giwa KT, Padilla G, Tejero $\mathrm{J}$ et al. Understanding the breast cancer experience of women: a qualitative study of African American, Asian American, Latina and Caucasian cancer survivors. Psycho-Oncology 2004; 13:408-428.

3. Matthews BA. Role and gender differences in cancer-related distress: a comparison of survivor and caregiver self-reports. Oncol Nurs Forum 2003;30(3): 493-499.

4. Mullens AB, McCaul KD, Erickson SC, Sandgren AK. Coping after cancer: risk perceptions, worry and health behaviors among colorectal cancer survivors. PsychoOncology 2004;13:367-376.

5. Walker BL. Adjustment of husbands and wives to breast cancer. Cancer Pract 1997;5(2):92-98.

6. Zahlis EH, Shands ME. Breast cancer demands of the illness on the patients partner. J Psychosoc Oncol 1991;9(1):75-93.

7. Stanton AL, Danoff-Burg S, Huggins ME. The first year after breast cancer diagnosis: hope and coping strategies as predictors of adjustment. Psycho-Oncology 2002; 11:93-102.

8. Vickberg S. The concerns about recurrence scale (CARS): a systematic measure of women's fears about the possibility of breast cancer recurrence. Ann Behav Med 2003;25(1):6-24.

9. Mellon S, Northouse LL, Weiss LK. A populationbased study of the quality of life of cancer survivors and their family caregivers. Cancer Nurs 2006;29(2): $120-131$

10. Ferrell BR, Grant MM, Funk B, Otis-Green S, Garcia N. Quality of life in breast cancer survivors as identified by focus groups. Psycho-Oncology 1997;6(1):13-23.

11. Ganz PA, Coscarelli A, Fred C, Kahn B, Polinsky ML, Petersen L. Breast cancer survivors: psychosocial concerns and quality of life. Breast Cancer Res Treat 1996;38(2):183-199.

12. Northouse LL. Mastectomy patients and the fear of cancer recurrence. Cancer Nurs 1981;4:213-220.

13. Davis-Ali SH, Chesler MA, Chesney BK. Recognizing cancer as a family disease: worries and support reported by patients and spouses. Soc Work Health Care 1993;19(2):45-65.

14. Harrison J, Haddad P, Maguire P. The impact of cancer on key relatives: a comparison of relative and patient concerns. Eur J Cancer 1995;31A(11):1736-1740.

15. Stefanek ME, Shaw A, DeGeorge D, Tsottles N. Illnessrelated worry among cancer patients: prevalence, severity, and content. Cancer Invest 1989;7(4): 365-371.

16. Mathews A, Ridgeway V, Warren R, Britton $\mathrm{P}$. Predicting worry following a diagnosis of breast cancer. Psycho-Oncology 2002;11:415-418.

17. Mellon S, Northouse LL. Family survivorship and quality of life following a cancer diagnosis. Res Nurs Health 2001;24:446-459.

18. McCubbin MA, McCubbin HI. Resiliency in families: a conceptual model of family adjustment and adaptation in response to stress and crises. In Family Assessment: Resiliency, Coping, and Adaptation-Inventories for Research and Practice, McCubbin HI, Thompson AI, McCubbin MA (eds). University of Wisconsin System: Madison, WI, 1996;1-64.

19. Bowman KF, Deimling GT, Smerglia V, Sage P, Kahana B. Appraisal of the cancer experience by older long-term survivors. Psycho-Oncology 2003;12(3):226238.

20. Härtl K, Janni W, Kästner R et al. Impact of medical and demographic factors on long-term quality of life and body image of breast cancer patients. Ann Oncol 2003;14:1064-1071.

21. Hilton A. The relationship of uncertainty, control, commitment, and threat of recurrence to coping strategies used by women diagnosed with breast cancer. J Behav Med 1989;12(1):39-54.

22. Gil KM, Mishel MH, Belyea $\mathrm{M}$ et al. Triggers of uncertainty about recurrence and long-term treatment side effects in older African American and Caucasian 
breast cancer survivors. Oncol Nurs Forum 2004;31(3): 633-639.

23. Maunsell E, Brisson J, Deschenes L. Psychological distress after initial treatment of breast cancer. Assessment of potential risk factors. Cancer 1992;70(1):120-125.

24. Northouse LL, Mood D, Kershaw T et al. Quality of life of women with recurrent breast cancer and their family members. J Clin Oncol 2002;20(19):4050-4064.

25. Bloom JR, Stewart SL, Chang S, Banks PJ. Then and now: quality of life of young breast cancer survivors. Psycho-Oncology 2004;13:147-160.

26. Ganz PA, Kwan L, Stanton AL et al. Quality of life at the end of primary treatment of breast cancer: first results from the moving beyond cancer randomized trial. J Natl Cancer Inst 2004;96(5):376-387.

27. Fife BL. The measurement of meaning in illness. Soc Sci Med 1995;40:1021-1028.

28. Carey PJ, Oberst MT, McCubbin MA, Hughes SH. Appraisal and caregiving burden in family members caring for patients receiving chemotherapy. Oncol Nurs Forum 1991;18:1341-1348.

29. Oberst MT, Thomas SE, Gass KA, Ward SE. Caregiving demands and appraisal of stress among family caregivers. Cancer Nurs 1989;12:209-215.

30. Baider L, Kaplan De-Nour A. Adjustment to cancer: who is the patient-the husband or the wife? Isr J Med Sci 1988;24(9-10):631-636.

31. Northouse LL, Mood D, Templin T, Mellon S, George T. Couples' patterns of adjustment to colon cancer. Soc Sci Med 2000;50:271-284.

32. Northouse LL, Templin T, Mood D. Couples' adjustment to breast disease during the first year following diagnosis. J Behav Med 2001;24(2):115-136.

33. McCubbin HI. Family Pressures Index. Family Stress, Coping and Health Project: Madison, WI, 1992.

34. McCubbin HI, Patterson J, Wilson L. Family inventory of life events and changes (FILE). In Family Assessment: Resiliency, Coping and Adaptation-Inventories for Research and Practice, McCubbin HI, Thompson AI, McCubbin MA (eds, 1996). University of Wisconsin System: Madison, WI, 1983;103-178.

35. Thompson EA, McCubbin HI, Thompson A, Elver KM. Vulnerability and resiliency in Native Hawaiian families under stress. In Resiliency in Ethnic Minority Families: Native and Immigrant American Families, vol. I, McCubbin HI, Thompson EA, Thompson AI, Fromer JE (eds). University of Wisconsin System: Madison, WI, 1995;115-131.

36. Cella DF, Tulsky DS, Gray G et al. The Functional Assessment of Cancer Therapy Scale: development and validation of the general measure. $J$ Clin Oncol 1993;11:570-579.

37. McCubbin MA, McCubbin HI, Thompson AI. Family Hardiness Index (FHI). In Family Assessment: Resiliency, Coping and Adaptation-Inventories for Research and Practice, McCubbin HI, Thompson AI, McCubbin MA (eds, 1996). University of Wisconsin System: Madison, WI, 1986;239-305.

38. McCubbin HI, Patterson J, Glynn T. Social Support Index (SSI). In Family Assessment: Resiliency, Coping and Adaptation-Inventories for Research and Practice, McCubbin HI, Thompson AI, McCubbin MA (eds, 1996). University of Wisconsin System: Madison, WI, 1982;357-389.

39. Germino BB, Fife BL, Funk SG. Cancer and the partner relationship: what is its meaning? Semin Oncol Nurs 1995;11:43-50.

40. Campbell L, Kashy DA. Estimating actor, partner, and interaction effects for dyadic data using PROC MIXED and HLM: a user-friendly guide. Pers Relat 2002;9(3):327-342.
41. Kashy DA, Kenny DA. The analysis of data from dyads and groups [References]. In Handbook of Research Methods in Social and Personality Psychology, Reis HT, Judd CM (eds). Cambridge University Press: New York, NY, 2000;451-477.

42. Kenny DA. Models of non-independence in dyadic research. J Soc Pers Relat 1996;13(2):279-294.

43. Kenny DA, Cook W. Partner effects in relationships research: conceptual issues, analytic difficulties, and illustrations. Pers Relat 1999;6:433-448.

44. Rayens MK, Svavarsdottir EK. A new methodological approach in nursing research: an actor, partner, and interaction effect model for family outcomes. Res Nurs Health 2003;26(5):409-419.

45. Badr H. Coping in marital dyads: a contextual perspective on the role of gender and health. Pers Relat 2004;11(2):197-211.

46. Bradford SA, Feeney JA, Campbell L. Links between attachment orientations and dispositional and diarybased measures of disclosure in dating couples: a study of actor and partner effects. Pers Relat 2002;9(4): 491-506.

47. Simpson JA, Orina MM, Ickes W. When accuracy hurts, and when it helps: a test of the empathic accuracy model in marital interactions. J Pers Soc Psychol 2003;85(5):881-893.

48. Whisman MA, Uebelacker LA, Weinstock LM. Psychopathology and marital satisfaction: the importance of evaluating both partners. J Consult Clin Psychol 2004;72(5):830-838.

49. Baron RM, Kenny DA. The moderatormediator variable distinction in social psychological research: conceptual, strategic, and statistical considerations. J Pers Soc Psychol 1986;51(6): $1173-1182$.

50. Hosmer DW, Lemeshow S. Applied Logistic Regression. Wiley: New York, 2000.

51. Aiken L, West S. Multiple Regression: Testing and Interpreting Interactions. Sage: Newbury Park, CA, 1991.

52. Northouse LL, Dorris G, Charron-Moore C. Factors affecting couples' adjustment to recurrent breast cancer. Soc Sci Med 1995;41(1):69-76.

53. Ell K, Nishimoto R, Mantell J, Hamovitch M. Longitudinal analysis of psychological adaptation among family members of patients with cancer. $J$ Psychosom Res 1988;32(4-5):429-438.

54. Cassileth BR, Lusk EJ, Strouse TB, Miller DS, Brown LL, Cross PA. A psychological analysis of cancer patients and their next-of-kin. Cancer 1985;55(1): $72-76$.

55. Oberst MT, Scott DW. Postdischarge distress in surgically treated cancer patients and their spouses. Res Nurs Health 1988;11(4):223-233.

56. Ganz PA, Descond KA, Leedham B, Rowland JH, Meyerowitz E, Belin TR. Quality of life in long-term, disease-free survivors of breast cancer: a follow-up study. J Natl Cancer Inst 2002;94(1):39-49.

57. Carver CS, Pozo C, Harris SD et al. How coping mediates the effect of optimism on distress: a study of women with early stage breast cancer. J Pers Soc Psychol 1993;65(2):375-390.

58. Lev EL, Paul D, Owen SV. Age, self-efficacy, and change in patients' adjustment to cancer. Cancer Pract 1999;7(4):170-176.

59. Edwards B, Clarke V. The psychological impact of a cancer diagnosis on families: the influence of family functioning and patients' illness characteristics on depression and anxiety. Psycho-Oncology 2004;13: 562-576. 